\title{
Enteroaggregative Escherichia coli Elaborate a Heat-Stable Enterotoxin Demonstrable in an In Vitro Rabbit Intestinal Model
}

Stephen J. Savarino, Alessio Fasano, Donald C. Robertson, * and Myron M. Levine

Division of Infectious Diseases and Tropical Pediatrics, Department of Pediatrics, University of Maryland School of Medicine,

Baltimore, Maryland 21201; and *Department of Microbiology, University of Kansas, Lawrence, Kansas 66045

\section{Abstract}

Enteroaggregative Escherichia coli (EAggEC) have been associated with persistent diarrhea in young children, but little is known about its pathogenesis. We assayed for enterotoxic activity in culture filtrates (CF) of EAggEC strains in Ussing chambers mounted with rabbit ileal mucosa. CF from strain 17-2, a prototype Chilean EAggEC strain, caused a greater rise in potential difference and short circuit current (SCC) than that seen in HB101 control, and this effect was abolished by protease pretreatment and partially stable after heat treatment. Ultrafiltration of 17-2 CF preparations localized the active moiety to the 2-5 $\mathrm{kD} M_{\mathrm{r}}$ size range. CF from $\mathrm{HB101}$ transformed with the 17-2 plasmid showed Ussing chamber activity. $<$ 10-kD CF fractions from five of six other EAggEC strains screened in Ussing chambers gave SCC responses of similar magnitude to 17-2. The 17-2 CF activity was not neutralized after pretreatment with polyclonal anti-STa antibody. Additionally, all of the seven EAggEC strains studied were nonreactive by heat-stable enterotoxin variant STa ELISA, were negative in the suckling mouse assay, and failed to hybridize with heat-stable enterotoxin variant STh and STp DNA probes. In summary, our data indicate that 17-2 produces a low molecular weight, partially heat-stable, protease-sensitive enterotoxin which appears to be plasmid associated, and genetically and immunologically distinct from $E$. coli STa. Preliminary screening suggests that this tox ${ }^{+}$phenotype may be common among EAggEC. (J. Clin. Invest. 1991. 87:1450-1455.) Key words: diarrhea • enteroaggregative Escherichia coli • enterotoxin • pathogenesis

Part of this work has previously been presented in abstract form: 90th Annual Meeting of the American Society of Microbiology, Anaheim, CA, 13-17 May 1990, Abstract B 112; Third Joint Meeting of ESPGAN/NASPGAN, Amsterdam, The Netherlands, 23-25 May 1990, Abstract 35.

Dr. Savarino's present address is Enteric Disease Division, Naval Medical Research Institute, Bethesda, MD 20814; Dr. Fasano's present address is Dipartimento di Pediatria, 2a Facolta di Medicina, Via S. Pansini, 5, Naples, Italy 80131.

Address reprint requests to Dr. Levine, University of Maryland School of Medicine, MSTF Room 9-36, 10 South Pine Street, Baltimore, MD 20814.

Received for publication 24 July 1990 and in revised form 17 October 1990.

1. Abbreviations used in this paper: CF, culture filtrate; EAggEC, EHEC, EIEC, EPEC, and ETEC, enteroaggregative, enterohemorrhagic, enteroinvasive, enteropathogenic, and enterotoxigenic $E$. coli; EAST, enteroaggregative $E$. coli heat-stable enterotoxin; PD, potential difference; SCC, short circuit current; STa, STh, and STp, E. coli heatstable enterotoxin variants.

J. Clin. Invest.

(c) The American Society for Clinical Investigation, Inc.

0021-9738/91/04/1450/06 \$2.00

Volume 87, April 1991, 1450-1455

\section{Introduction}

Several categories of Escherichia coli have been firmly established as important enteropathogens, including enteropathogenic $E$. coli (EPEC), ${ }^{1}$ enterotoxigenic $E$. coli (ETEC), enteroinvasive $E$. coli (EIEC), and enterohemorrhagic $E$. coli (EHEC) (1). Recently, evidence has accumulated to implicate a fifth distinct diarrheagenic category, enteroaggregative $E$. coli (EAggEC). EAggEC derive their name from their pattern of adherence to HEp-2 cells in tissue culture (2), whereby the organisms adhere to HEp- 2 cells and the intervening glass in a "stacked brick"-like lattice. Several epidemiological studies have implicated EAggEC as a cause of diarrhea in infants and young children (3-5), noting a particularly strong association with children exhibiting persistent diarrhea $(4,5)$.

$E$. coli strain 221, which was isolated from an adult traveler to Mexico who had diarrhea, exhibits the aggregative pattern when tested in the HEp- 2 cell assay used at the Center for Vaccine Development, University of Maryland (6), a modification of the 3-h assay of Cravioto et al. (7). Strain 221 caused diarrhea when fed to adult volunteers (8). Recently, strains 221 and 17-2, a prototype EAggEC strain from Chile, have been shown to cause diarrhea in the gnotobiotic piglet model (9).

EAggEC share some common themes with other categories of diarrheagenic $E$. coli. Certain O:H serotypes are common (10). Virtually all strains contain an $\sim 60-\mathrm{MD}$ plasmid which is required for expression of the aggregative phenotype (10). Preliminary insights on the pathogenesis of EAggEC infection have been gained from studies in gnotobiotic piglets (reference 9 and Tzipori, S., J. Montenaro, R. M. Robins-Browne, P. Vial, R. Gibson, and M. M. Levine, manuscript submitted for publication). EAggEC adhered to piglet ileal mucosa in a continuous sheet in a "stacked brick" pattern similar to what is seen in vitro in the HEp- 2 cell adherence assay. According to Tzipori et al., certain pathological changes observed in the intestine, namely, moderate hyperemia of the distal small intestine and cecum, swelling of small intestinal villi, and absence of an inflammatory response, are compatible with an enterotoxin-induced diarrheal response.

The in vitro Ussing chamber model has proven invaluable for study of the mechanisms of action of enterotoxins on mammalian intestinal mucosa. Choleragen and heat-stable enterotoxin variant STa of ETEC have been shown to cause an increase in the short circuit current (SCC) of ileal mucosa by stimulation of a net anion secretory flux $(11,12)$. In the present study we employed this system to assay for enterotoxic activity in cell-free culture filtrates of representative EAggEC strains, and further undertook to characterize the nature of the enterotoxic moiety elaborated by the prototype EAggEC strain 17-2.

\section{Methods}

Bacterial strains. Prototype EAggEC strain 17-2 was isolated from a Chilean infant with diarrhea (10). EAggEC strains 73-1, 121-2, and 2036 were obtained from other Chilean infants with diarrhea. EAggEC strains $34 b, 44 a$, and 134a were derived from a cohort of rural Indian 
children with diarrhea (4). E. coli strain HB101 served as a negative control and was also used as the recipient for the transformation of the $\sim 60$-MD plasmid of strain 17-2. Briefly, the latter construction, re-

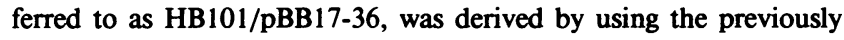
described system of SM10/pRT733 (13) to deliver TnphoA into the strain 17-2. Unexpectedly, all the $\mathrm{Km}^{\mathrm{r}}$ clones harvested were also $\mathrm{Ap}^{\mathrm{r}}$ and, therefore, still contained the suicide vector pRT733. After culture of these strains at $42^{\circ} \mathrm{C}, \mathrm{Km}^{\mathrm{r}} \mathrm{Ap}$ clones were isolated. Plasmid DNA was extracted from the clones and used to transform competent cells of HB101. Transformants were selected for $\mathrm{Km}^{\mathrm{r}}$.

Culture conditions and preparation of culture filtrate fractions. Strain 17-2 was streaked to isolation and grown overnight at $37^{\circ} \mathrm{C}$ on Luria Bertani agar (14). Isolated colonies were inoculated into a $250-\mathrm{ml}$ Erlenmeyer flask containing $25 \mathrm{ml}$ of Luria Bertani medium (14), adjusting the initial absorbance at $600 \mathrm{~nm}(\mathrm{OD} 600)$ to 0.05 . After $8 \mathrm{~h}$ of incubation at $37^{\circ} \mathrm{C}$ with shaking $(200 \mathrm{rpm})$, an aliquot of the starter culture was added to $300 \mathrm{ml}$ of Luria Bertani medium in a 2.8-liter baffled Erlenmeyer flask, to achieve a starting OD 600 of 0.05 . After 12 $h$ of growth under the above conditions, the cultures were harvested. Cell-free culture filtrate (CF) was obtained by centrifugation at 16,000 $g$ for $10 \mathrm{~min}$, and passage of the decanted supernatant through a 0.45 $\mu \mathrm{m}$ filter membrane (Millipore Products, Bedford, MA).

CF of 17-2 was fractionated on the basis of molecular weight using a series of Diaflo ultrafilters (Amicon Corp., Danvers, MA). Centricon10 filters $(10,000$-mol wt cutoff $)$ were used in preliminary experiments to localize the enterotoxic activity detected in Ussing chamber experiments. Subsequently, CF was serially ultrafiltered through YM5 (5,000-mol wt cutoff) and either YM2 (2,000-mol wt cutoff) or YC05 (500-mol wt cutoff) membranes, to produce fractions defined by these size limits. Membrane retentates were washed with PBS (Oxoid) by two successive 10:1 volume restorations with PBS, reconcentration, and final reconstitution to the original volume (or some factor of concentration) in PBS. Fractions from strains HB101/pBB17-36 and HB101 were generated in the same fashion as 17-2.

All wild-type EAggEC strains other than 17-2 were grown under conditions similar to 17-2 except that subculturing was done into $25 \mathrm{ml}$ of LB medium in 250-ml Erlenmeyer flask prior to harvesting. For purposes of screening these strains for a low molecular weight moiety with enterotoxic activity in Ussing chambers, culture filtrates were passed through a Centricon-10 membrane, and the ultrafiltrate was assayed for activity.

EAggEC CF and CF fractions as prepared above were also used for testing in the competitive STa ELISA (15) and suckling mouse assay (16).

Ussing chamber experiments. All experiments were performed on segments of small intestine from male adult New Zealand white rabbits weighing $\sim 2-3 \mathrm{~kg}$. Animals were anesthetized by methoxyflurane inhalation and then killed by air embolism. A $15-\mathrm{cm}$ segment of distal ileum was removed, rinsed free of intestinal contents, opened along the mesenteric border, and stripped of muscular and serosal layers as previously described (17). Four sheets of mucosa so prepared were then mounted in lucite Ussing chambers having an aperture of $1.12 \mathrm{~cm}^{2}$, bathed by freshly prepared buffer containing $(\mathrm{mM}): \mathrm{NaCl} 53, \mathrm{KCl} 5$, $\mathrm{Na}_{2} \mathrm{SO}_{4} 30.5$, mannitol 30.5, $\mathrm{Na}_{2} \mathrm{HPO}_{4} 1.69, \mathrm{NaH}_{2} \mathrm{PO}_{4} 0.3, \mathrm{CaCl}_{2} 1.25$, $\mathrm{MgCl}_{2}$ 1.1, $\mathrm{NaHCO}_{3} 25$. For experiments performed in $\mathrm{Cl}^{-}$and $\mathrm{HCO}_{3}^{-}-$ free conditions, these ions were replaced with an equimolar concentration of $\mathrm{SO}_{4}^{-}$in the bathing solutions. The bathing solution was maintained at $37^{\circ} \mathrm{C}$ with water-jacketed reservoirs connected to a constanttemperature circulating pump and gassed with $95 \% \mathrm{O}_{2}-5 \% \mathrm{CO}_{2}$. Potential difference (PD), short circuit current (SCC), and tissue resistance $\left(R_{t}\right)$ were then measured as previously described (18). After allowing tissue PD to reach a steady state, $400 \mu$ l of each test preparation were added to the luminal surface, resulting in a 1:25 dilution of the original CF concentration ( $0.4 \mathrm{ml}$ into $10 \mathrm{ml}$ bathing solution). Equal amounts of the test preparation were added to the serosal side to preserve osmotic balance.

Suckling mouse assay. Suckling mouse assay for $E$. coli STa activity was performed as described previously (16). CD1 mice (3-5 d old) were separated from their mothers for 3-5 $\mathrm{h}$ before orogastric inoculation of
$0.1 \mathrm{ml}$ of the supernatant fraction to be tested. After a 2-3-h incubation, gut to remaining body weight $(\mathrm{G} / \mathrm{B})$ ratios were measured for each individual animal. Additionally, 17-2 CF was also tested after 5 and $7 \mathrm{~h}$ of incubation. ETEC strain H10407 (ST/LT producer) and PBS were used as positive and negative control, respectively.

Competitive STa ELISA. The competitive ELISA for E. coli STa using monoclonal antibody 20clB8 (19) has been described elsewhere (15). For screening purposes, a strain was considered STa-positive when a CF concentration of $20 \mathrm{ng} / \mathrm{ml}$ of STa was measured in the ELISA. ETEC strain $\mathrm{H} 10407$ was used as a positive control for this assay.

Colony hybridization with STh and STp DNA probes. All strains were assayed for DNA homology with genes encoding for two variants of heat-stable enterotoxin, STh and STp. The STh and STp probe fragments originally used by Moseley et al. (20) had previously been recloned into pBR325 using synthetic oligonucleotide linkers (21). Subsequently, the 157-bp Pst I fragment of STp and the 216-bp EcoRI fragment of STh have been recloned into pUC 13, giving higher yields of the probe fragments. It is from the latter vectors that the STh and STp DNA probe fragments were derived for this study. The probes were radiolabeled with $\left[{ }^{32} \mathrm{P}\right] \mathrm{dATP}$ (New England Nuclear, Boston, MA) using the random primer method (22). Colonies were prepared on Whatman 541 filter paper (23). In situ hybridization with the radiolabeled fragments was performed as described (24) with modifications to provide conditions of low stringency. Preincubation and hybridization solutions contained $20 \%$ formamide. After overnight incubation, filters were washed in $5 \times \mathrm{SSC}$ with $0.1 \%$ SDS for $1 \mathrm{~h}$ at $51^{\circ} \mathrm{C}$. $\mathrm{HB} 101$ and $\mathrm{H} 10407$ were added to each filter as negative and positive controls, respectively.

Reagents. Where indicated, theophylline (5 mM), 4-bromo-calcium ionophore (A23187) $\left(5 \times 10^{-7} \mathrm{M}\right)$, and 8-bromo-cGMP (8-BrcGMP) (0.2 mM) (Sigma Chemical Co., St. Louis, MO) were added to the serosal side of Ussing half chambers to the final concentration shown in parentheses. Proteinase K (Sigma Chemical Co.) was used to pretreat active CF fractions of strain 17-2 at a concentration of 200 $\mu \mathrm{g} / \mathrm{ml}$ for $1 \mathrm{~h}$ at $37^{\circ} \mathrm{C}$. Polyclonal anti-STa was obtained after crosslinkage of STa-BSA with glutaraldehyde as previously described (25) and was preincubated with active 17-2 CF fraction at a dilution of $1: 10$ $\left(3 \mathrm{~h}\right.$ at $\left.37^{\circ} \mathrm{C}\right)$ in cross-neutralization studies. Before these experiments, a 1:10 dilution was shown to abolish the SCC response of 300 mouse units of purified STa in Ussing chambers after 3-h incubation at $37^{\circ} \mathrm{C}$.

Data analysis. The numerical data presented from Ussing chamber experiments and SMA are expressed as mean \pm standard error. Paired or unpaired $t$ tests or analysis of variance were used to test for differences among means. Multiple comparisons were obtained by Sidak (for analysis of variance) or Bonferroni (for $t$ tests) methods. A critical $P$ value of 0.05 was used for all analyses.

\section{Results}

Effect of 17-2 CF and CF fractions on SCC. Preliminary Ussing chamber experiments aimed at detecting the presence of enterotoxic effect on rabbit ileal mucosa as measured by a change in SCC were performed using crude CF. The overall increase in PD and SCC was significantly greater for 17-2 CF as compared to $\mathrm{HB} 101$ negative control (Table I). Pretreatment of the crude $\mathrm{CF}$ with proteinase $\mathrm{K}$ abolished the effect on SCC ( $\triangle \mathrm{SCC}$ $=3 \pm 4.5 \mu \mathrm{A} / \mathrm{cm}^{2}$ after proteinase $\mathrm{K}$ pretreatment vs. $\Delta \mathrm{SCC}$ $=49.3 \pm 10.2 \mu \mathrm{A} / \mathrm{cm}^{2}$ untreated $\left.[n=2]\right)$, suggesting that the active moiety is protein in nature.

To approximate the size of the active moiety, we tested a series of CF fractions separated on the basis of $M_{\mathrm{r}}$ by ultrafiltration through Diaflo membranes. As shown in Fig. 1, fractions $>10 \mathrm{kD}$ and $<0.5 \mathrm{kD}$ in $M_{\mathrm{r}}$ failed to produce a rise in SCC. In contrast, fractions of $<10 \mathrm{kD}$ and $<5 \mathrm{kD} M_{\mathrm{r}}$ produced an effect of similar magnitude to the crude $\mathrm{CF}$, and a $2-5-\mathrm{kD}$ retentate fraction produced a rise in SCC that was statistically 


\begin{tabular}{|c|c|c|c|c|}
\hline Strain & CF fraction & $n$ & PD & SCC \\
\hline & & & $m V$ & $\mu A / \mathrm{cm}^{2}$ \\
\hline HB101 & Crude CF (negative control) & 5 & $0.48 \pm 0.15$ & $16.8 \pm 3.0$ \\
\hline $17-2$ & Crude CF & 11 & $0.99 \pm 0.09^{\S}$ & $37.8 \pm 3.6^{5}$ \\
\hline $17-2$ & $<500$-D filtrate (negative control) & 4 & $0.38 \pm 0.13$ & $18.6 \pm 3.7$ \\
\hline $17-2$ & $2-5-\mathrm{kD}$ retentate (positive control) & 4 & $1.32 \pm 0.19$ & $55.2 \pm 2.8$ \\
\hline $17-2$ & 2-5-kD retentate: heat treated ${ }^{*}$ & 4 & $0.88 \pm 0.10$ & $35.0 \pm 3.8^{\prime \prime}$ \\
\hline $17-2$ & 2-5-kD retentate: anti-STa treated ${ }^{\ddagger}$ & 4 & $1.60 \pm 0.21$ & $62.0 \pm 0.8^{11}$ \\
\hline HB101 & 2-5-kD retentate (negative control) & 4 & $0.42 \pm 0.19$ & $16.0 \pm 3.7$ \\
\hline HB101/pBB17-36 & $2-5-\mathrm{kD}$ retentate & 4 & $1.08 \pm 0.18$ & $38.7 \pm 5.8^{\prime}$ \\
\hline
\end{tabular}

* Preparation pretreated at $65^{\circ} \mathrm{C}$ for $15 \mathrm{~min}$. ${ }^{\ddagger}$ Preparation pretreated with $1: 10$ dilution of polyconal anti-STa antibody for $3 \mathrm{~h}$ at $37^{\circ} \mathrm{C}$. ${ }^{8} P$ $<0.01$ compared to HB101 CF (negative control) $(t$ test). "Heat-treated preparation significantly lower than positive control and higher than negative control; anti-STa-treated preparation significantly higher than negative control (randomized blocks ANOVA with rabbits as blocks, and one-tailed Sidak comparisons). ' $P=0.028$ compared to HB101 2-5-kD retentate (negative control) (randomized blocks ANOVA with rabbits as blocks).

homogeneous and significantly higher than the previous two fractions (analysis of variance, Sidak comparisons). The active moiety appears to reside between 2,000 and 5,000 D $M_{\mathrm{r}}$.

In order to determine the effect of heat on the activity, 2-5-kD fractions of $17-2 \mathrm{CF}$ were preheated at $65^{\circ} \mathrm{C}$ for $15 \mathrm{~min}$ before assay in Ussing chambers. As shown in Table I, after heat treatment this fraction maintained $63 \%$ of total activity, demonstrating at least partial heat stability.

The intestinal response to most known secretagogues is mediated by one of the three established second messengers; namely, cAMP, cGMP, or calcium. To determine the possible intracellular mediator of the electrical response to 17-2 CF, theophylline (a potent cAMP agonist), A23187 (calcium ionophore), and 8-Br-cGMP (cGMP analogue) were added to tissues pretreated with either 17-2 CF 2-5-kD fraction or $<0.5-\mathrm{kD}$ fraction (negative control). The mean change in SCC after addition of theophylline to positive and negative control

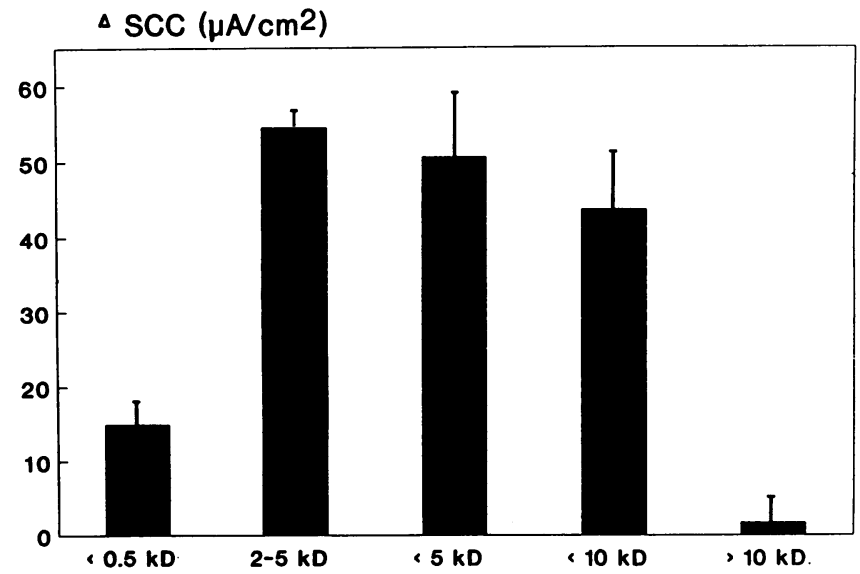

Figure 1. Total increase in SCC after steady state achieved after addition of various size-delineated 17-2 CF fractions to rabbit ileal mucosa mounted in Ussing chambers. Two homogeneous sets of fractions are indicated: fractions between 2,000 and $10,000 \mathrm{D}$ show significantly higher $\triangle S C C$ than the remaining two fractions (ANOVA and Sidak comparisons). tissues was $132.2 \pm 30.8$ and $141.2 \pm 10.4 \mu \mathrm{A} / \mathrm{cm}^{2}(n=2)(P$ $=$ NS, paired $t$ test), respectively. The mean change in SCC after addition of $\mathrm{A} 23187$ to positive and negative control tissues was $96.6 \pm 26.5$ and $78.8 \pm 8.8 \mu \mathrm{A} / \mathrm{cm}^{2}(n=3)(P=\mathrm{NS}$, paired $t$ test), respectively. The additivity of SCC responses to 17-2 CF active fractions with these second messenger agonists does not support a role for either cAMP or calcium as possible intracellular mediators of this enterotoxic effect. In contrast, as shown graphically in Fig. 2, compared to the SCC response to $8-\mathrm{Br}-\mathrm{cGMP}$ in negative control tissue $(\triangle \mathrm{SCC}=123.4 \pm 7.9 \mu \mathrm{A} /$ $\mathrm{cm}^{2}$ ), the $\triangle \mathrm{SCC}$ with addition of $8-\mathrm{Br}-\mathrm{cGMP}$ to tissue pretreated with 17-2 2-5-kD CF $\left(87.6 \pm 8.2 \mu \mathrm{A} / \mathrm{cm}^{2}\right)$ was significantly less $(P<0.01)$. Further, the additive effect of 17-2 2-5$\mathrm{kD} \mathrm{CF}$ and 8-Br-cGMP $\left(\triangle \mathrm{SCC}=142.8 \pm 9.1 \mu \mathrm{Amp} / \mathrm{cm}^{2}\right)$ was not significantly different compared to the SCC response to

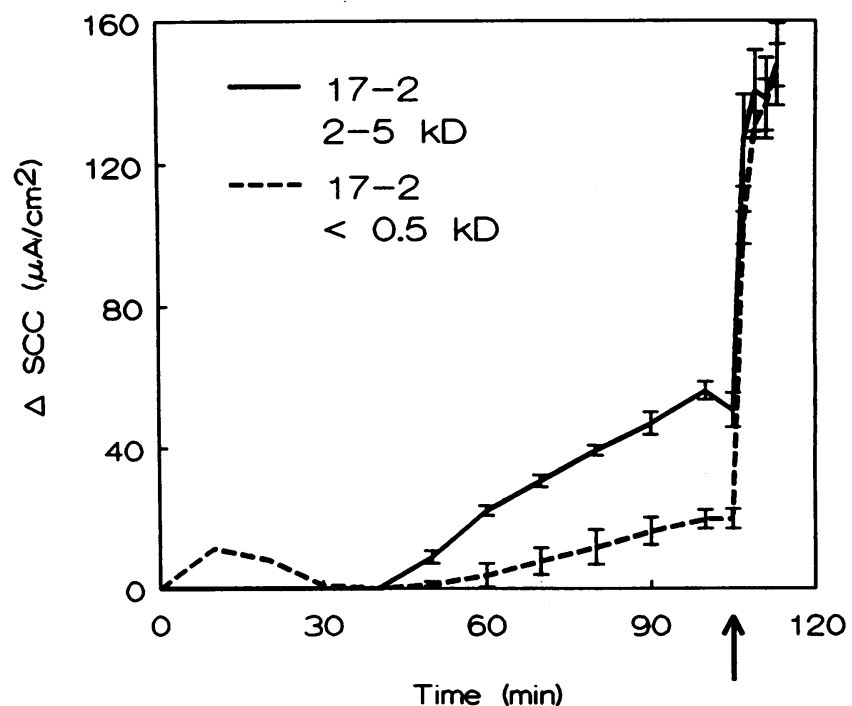

Figure 2. Time course of $\mathrm{SCC}$ response after addition of 17-2 2-5-kD CF fraction vs. $17-2<0.5-\mathrm{kD}$ CF fraction to rabbit ileal mucosa mounted in Ussing chambers. Means \pm standard errors $(n=4)$ are plotted. At the peak of response 8-Br-cGMP $(0.2 \mathrm{mM})$ was added to the serosal surface (indicated by arrow). 
8-Br-cGMP in negative control tissue as noted above ( $P$ $>0.05$ ). Furthermore, pretreatment of tissue with 8-Br-cGMP resulted in abolition of the response to 17-2 CF. The mean increase in SCC after addition of 17-2 CF to untreated (positive control) vs. 8-Br-cGMP pretreated tissue was $+38.6 \pm 0.04 \mu \mathrm{A} /$ $\mathrm{cm}^{2}$ compared to $+6.7 \mu \mathrm{A} / \mathrm{cm}^{2}(n=2)$. These data constitute preliminary, indirect evidence that cGMP may be acting as second messenger.

In response to other $E$. coli enterotoxins, cyclic nucleotide levels within intestinal epithelial cells are increased, resulting in a net active anion secretion (12). We indirectly examined the possible role of $\mathrm{Cl}^{-}$and $\mathrm{HCO}_{3}^{-}$as they relate to the overall increase in SCC caused by 17-2 active fractions. As shown in Fig. 3, under both $\mathrm{Cl}^{-}$-free and $\mathrm{HCO}_{3}^{-}$-free conditions, the $\mathrm{SCC}$ variation owing to the $2-5-\mathrm{kD}$ fraction was significantly less than that seen when normal Ringer's solution was used ( $t$ tests with Bonferroni approximation). This suggests that both $\mathrm{Cl}^{-}$ and $\mathrm{HCO}_{3}^{-}$may be involved in the electrical response engendered by 17-2 CF.

Since this putative enterotoxin shares certain features with $E$. coli $\mathrm{STa}$, such as its small size, relative heat stability, and the finding that cGMP may be acting as second messenger, we sought evidence of possible immunological relatedness. 17-2 2-5-kD CF fractions were preincubated with polyclonal antiSTa before addition to the rabbit ileal mucosa in the Ussing chamber. As shown in Table I, no cross-neutralization was observed after anti-STa preincubation, suggesting a lack of immunological cross-reactivity. To provide a baseline for these experiments, we examined the effect of purified STa on Ussing chamber-mounted ileal tissue. Addition of 100, 300, and 1,000 mouse units to the mucosal half-chamber resulted in an increase in SCC of $27.2(n=1), 49.1(n=2)$, and $55.7(n=1)$ $\mu \mathrm{A} / \mathrm{cm}^{2}$, respectively. After preincubation of 300 mouse units of STa with polyclonal anti-STa, a rise in SCC of $8.6 \mu \mathrm{A} / \mathrm{cm}^{2}$ was observed, demonstrating complete abolition of the secretory response.

We next examined the effect of a $2-5-\mathrm{kD} M_{\mathrm{r}}$ CF fraction from $\mathrm{HB} 101 / \mathrm{pBB} 17-36$ on $\mathrm{PD}$ and $\mathrm{SCC}$ as compared to HB101 CF fraction produced in the same manner. As shown in Table I, paired variate analysis showed a significantly larger incremental PD and SCC response to the $\mathrm{HB101/pBB17-36}$ as

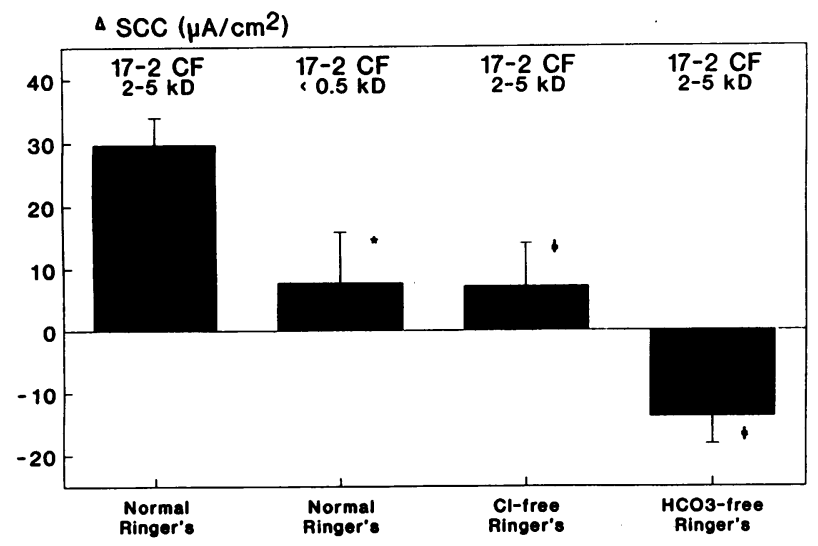

Figure 3. Total change in SCC after addition of 17-2 2-5-kD CF fraction to rabbit ileal mucosa bathed in normal Ringer's solution vs. $\mathrm{Cl}^{-}$-free or $\mathrm{HCO}_{3}^{-}$-free Ringer's. ${ }^{*} P<0.05$ and $\ddagger P<0.01$ compared to positive control by paired $t$ test $(n=6)$ with Bonferroni approximation applied. compared to the negative control. These data indicate that the presence of the plasmid is required for expression of the enterotoxic activity.

In all of the above experiments the increments seen in SCC were accompanied by parallel increases in the PD after addition of test samples. Changes in $R_{\mathrm{t}}$ of $\leq 10 \%$ were observed. As an example, the percent change in $R_{\mathrm{t}}$ after addition of $2-5-\mathrm{kD}$ $\mathrm{CF}$ fractions from $\mathrm{HB} 101$ and $\mathrm{HB} 101$ (pBB17-36) was $-4.5 \%$ and $-2.4 \%$, respectively. These responses do not reflect a significant drop in tissue resistance. Furthermore, selected sheets of rabbit ileal mucosa appeared morphologically normal after exposure to 17-2 CF preparations when examined by light and electron microscopy (data not shown).

To determine the frequency of this tox ${ }^{+}$phenotype among EAggEC strains, we screened $<10-\mathrm{kD}$ CF fractions from six other EAggEC strains, three each from young children with diarrhea in Chile and India. As can be seen in Table II, six of six of these strains produced a SCC greater than the negative controls, and five of six gave responses of similar magnitude to preparations from 17-2.

Suckling mouse assay. The suckling mouse assay, the standard bioassay for detection of STa, was evaluated as a possible model for secretion for the Ussing chamber-active moiety elaborated by strain 17-2. Most investigators define a positive response as a G/B ratio of 0.083 or greater (21). Concentrates of $20 \times$ and $50 \times$ of the 2-5-kD $M_{\mathrm{r}}$ CF fraction from 17-2 were inoculated into suckling mice and at $3 \mathrm{~h}$ gave $\mathrm{G} / \mathrm{B}$ ratios of $0.064 \pm 0.001(n=16)$ and $0.068 \pm 0.002(n=5)$, respectively. Additionally, crude CF from 17-2 were tested after 5- and 7-h incubation periods and gave $\mathrm{G} / \mathrm{B}$ ratios of $0.054 \pm 0.004(n=2)$ and $0.059 \pm 0.001(n=4)$, respectively. The other six EAggEC strains examined in this study also gave negative responses in the suckling mouse assay, as seen in Table II. In all experiments, ETEC strain H10407 and PBS were used as positive and negative controls, and always gave $G / B$ ratios of $\geq 0.120$ and $\leq 0.064$, respectively.

STh and STp DNA hybridization. Under conditions of low stringency none of the seven EAggEC strains examined in this study hybridized with the DNA probes for STh or STp, while

Table II. Mean Total Increase in SCC of Rabbit Ileal Mucosa in Ussing Chambers, and Suckling Mouse Assay Results for Seven EAggEC Isolates from Chile and India

\begin{tabular}{|c|c|c|c|c|}
\hline Strain & Serotype & Origin & Mean $\Delta \operatorname{SCC}^{*}(n)$ & $\begin{array}{c}\text { Suckling mouse assay } \\
\text { G/B ratio }(n)\end{array}$ \\
\hline & \multicolumn{4}{|c|}{$\mu A / \mathrm{cm}^{2}$} \\
\hline $17-2$ & $\mathrm{O} 3: \mathrm{H} 2$ & Chile & $+43.6(4)$ & $0.064 \pm 0.001(16)$ \\
\hline $73-1$ & O73:H33 & Chile & $+55.2(2)$ & $0.057 \pm 0.002(6)$ \\
\hline $121-2$ & O78:H33 & Chile & $+35(2)$ & $0.059 \pm 0.001(8)$ \\
\hline 2036 & O3:H2 & Chile & $+26.1(2)$ & $0.059 \pm 0.001(8)$ \\
\hline $34 b$ & O?:NM & India & $+60.2(2)$ & $0.06 \pm 0.002(4)$ \\
\hline $44 a$ & O77:H? & India & $+38.3(2)$ & $0.061 \pm 0.002(6)$ \\
\hline $134 a$ & O?:NM & India & $+43.7(2)$ & $0.059 \pm 0.002(8)$ \\
\hline \multicolumn{5}{|l|}{ Negative } \\
\hline control $^{8}$ & & & $+19.1(6)$ & \\
\hline
\end{tabular}

$*$ 10-kD CF fractions added to Ussing chamber.

$\ddagger 0.1$ of ml crude CF orogastrically inoculated into each mouse.

Negative controls were composed of $>10-\mathrm{kD}$ CF retentates from one of the test strains in each experimental run. 
the HB101 and H10407 control strains were negative and positive, respectively.

\section{Discussion}

The present study establishes that a substance excreted by the prototype EAggEC strain 17-2 induces ion transport alterations consistent with a secretory response. The significant rise in SCC after addition of 17-2 CF preparations to rabbit ileal mucosa in Ussing chambers, which is ablated under $\mathrm{HCO}_{3}^{-}$or $\mathrm{Cl}^{-}$-free conditions, supports this contention. Our studies suggest that this substance is protein in nature, protease sensitive, between 2,000 and 5,000 D in $M_{\mathrm{r}}$, at least partially heat-stable, and plasmid associated. Second messenger data are compatible with the hypothesis that CGMP acts as the intracellular mediator of this response. We have named this substance enteroaggregative $E$. coli heat-stable enterotoxin (EAST 1).

The size and heat stability of EAST 1 , as well as the second messenger data, are attributes shared with $E$. coli STa. There exist a family of heat-stable enterotoxins which are structurally and functionally highly related to STa, share varying degrees of amino acid homology and immunological cross-reactivity, and are all active in the suckling mouse assay. To date, such STs have been associated with Yersinia enterocolitica (26), Non-01 Vibrio cholerae (27), Klebsiella pneumoniae (28), and Citrobacter freundii (29). Unlike these other STs, EAST 1 does not appear to be immunologically cross-reactive with STa, as shown by its nonreactivity in the competitive STa ELISA and absence of cross-neutralization by polyclonal anti-STa in the Ussing chamber model. Also, EAST 1 is not active in the suckling mouse assay under conditions in which STa is active.' Furthermore, as suggested by DNA hybridization data, EAST 1 also appears to be genetically distinct from STa.

The mean time until onset of enterotoxic action, as measured by the increase in SCC after addition of CF preparations of 17-2, ranges between 30 and $40 \mathrm{~min}$. This differs from the immediate onset of enterotoxic effect when preparations of $E$. coli STa or STb are added to the mucosal surface in the Ussing chamber system. It is not clear if the kinetics of EAST 1 action are somehow affected by using a crude vs. pure preparation, or if this reflects a true difference related to the cascade of events which intercede the binding of EAST 1 to enterocyte receptors and the ultimate secretory response. Although our purpose was not to define the specific alterations in active ion transport engendered by EAST 1, the experiments in $\mathrm{Cl}^{-}$and $\mathrm{HCO}_{3}^{-}$-free conditions suggest that active transport of one or both of these anions may be involved. Interestingly, our current understanding is that the mechanisms of action of STa and STb predominantly involve the active secretion of $\mathrm{Cl}^{-}$and $\mathrm{HCO}_{3}^{-}$, respectively $(30,31)$. Further study related to the kinetics and exact mechanism of action of EAST 1 awaits purification of this moiety.

Both the aggregative phenotype (10) and EAST 1 production are plasmid associated properties. Colonization factors and enterotoxins elaborated by ETEC strains require the presence of plasmids (32). We suggest that the $\sim 60$-MD plasmid, which is highly conserved among strains of EAggEC (33), represents a critical virulence determinant. Data from the gnotobiotic piglet model showing in vivo aggregation of EAggEC on the ileal mucosal surface suggest that this phenotype may correlate with colonization of the small intestine of infected hosts. We postulate that aggregative adherence along the mucosal border may also serve to create a microenvironment whereby EAST 1 and perhaps other exotoxins are secreted in close proximity to the enterocyte surface protected from luminal proteases and other degradative processes.

Ussing chamber screening of $<10-\mathrm{kD}$ CF fractions from a limited number of EAggEC isolates from children with diarrhea in India and Chile showed that five of six elicited an increase in SCC of similar or greater magnitude as compared to prototype strain 17-2. As with 17-2, preparations from these strains were negative on testing in the suckling mouse assay and STa ELISA, and colonies did not hybridize at low stringency with DNA probes for STh or STp. Since some common serotypes are seen among these strains, all contain an $\sim 60$ MD plasmid of which all but one hybridize with a newly developed DNA probe for EAggEC (33), and the Ussing chamberactive moieties are all in the same size range $\left(<10 \mathrm{kD} M_{\mathrm{r}}\right)$, we predict that EAST 1 may be a common virulence property among EAggEC. Clearly, further studies are necessary to prove DNA and polypeptide homology among these candidate enterotoxin-producing EAggEC. Additionally, development of a simple and reliable biological or immunological assay for EAST 1 will facilitate large-scale screening of EAggEC for enterotoxin production, as well as facilitate purification of this novel enterotoxin.

\section{Acknowledgments}

The authors thank David Jacoby for his generous technical support. We acknowledge Steven S. Wasserman for his assistance in data analysis. We also thank Wendy Martin and David Maneval for technical assistance.

This work was supported in part by National Institutes of Health Contract N01-AI-62528 to Myron M. Levine.

\section{References}

1. Levine, M. M. 1987. Escherichia coli that cause diarrhea: enterotoxigenic, enteropathogenic, enteroinvasive, enterohemorrhagic, and enteroadherent. J. Infect. Dis. 155:377-389.

2. Nataro, J. P., J. B. Kaper, R. Robins-Browne, V. Prado, P. A. Vial, and M. M. Levine. 1987. Patterns of adherence of diarrheagenic Escherichia coli to HEp-2 cells. J. Ped. Infect. Dis. 16:829-831.

3. Levine, M. M., V. Prado, R. Robins-Browne, H. Lior, J. B. Kaper, S. L. Moseley, K. Gicquelais, J. P. Nataro, P. Vial, and B. Tall. 1988. Use of DNA probes and HEp-2 cell adherence assay to detect diarrheagenic Escherichia coli. J. Infect. Dis. 158:224-228.

4. Bhan, M. K., P. Raj, M. M. Levine, J. B. Kaper, N. Bhandari, R. Srivastava, R. Kumar, and S. Sazawal. 1989. Enteroaggregative Escherichia coli associated with persistent diarrhea in a cohort of rural children in India. J. Infect. Dis. 159:1061-1064.

5. Bhan, M. K., V. Khoshoo, H. Sommerfelt, R. Pushker, S. Sazawal, and R. Srivastava. 1989. Enteroaggregative Escherichia coli and Salmonella associated with nondysenteric persistent diarrhea. Pediatr. Infect. Dis. J. 8:499-502.

6. Vial, P. A., J. J. Mathewson, H. L. DuPont, L. Guers, and M. M. Levine. 1990. Comparison of two assay methods for patterns of adherence to HEp- 2 cells of Escherichia coli from patients with diarrhea. J. Clin. Microbiol. 28:882-885.

7. Cravioto, A., R. J. Gross, S. M. Scotland, and B. Rowe. 1979. An adhesive factor found in strains of Escherichia coli belonging to the traditional enteropathogenic serotypes. Curr. Microbiol. 3:95-99.

8. Mathewson, J. J., P. C. Johnson, H. L. DuPont, T. K. Satterwhite, and D. K. Winsor. 1986. Pathogenicity of enteroadherent Escherichia coli in adult volunteers. J. Infect. Dis. 154:524-527.

9. Levine, M. M. 1989. Enteroaggregative Escherichia coli: a new diarrheal agent. In Proceedings of the Federation of European Microbiological Societies Workshop on Microbial Surface Components and Toxins in Relation to Pathogenesis. E. Z. Ron, editor.

10. Vial, P. A., R. Robins-Browne, H. Lior, V. Prado, J. B. Kaper, J. P. Nataro, D. Maneval, A. Elsayed, and M. M. Levine. 1988. Characterization of enteroadherent-aggregative Escherichia coli, a putative agent of diarrheal disease. J. Infect. Dis. 158:70-79. 
11. Field, M., D. Fromm, Q. Al-Awqati, and W. B. Greenough III. 1972. Effect of cholera enterotoxin on ion transport across isolated ileal mucosa. J. Clin Invest. 51:796-804.

12. Field, M., L. H. Graf, Jr., W. J. Laird, and P. L. Smith. 1978. Heat-stable enterotoxin of Escherichia coli: in vitro effects on guanylate cyclase activity, cyclic GMP concentration, and ion transport in small intestine. Proc. Natl. Acad. Sci. USA. 75:2800-2804.

13. Taylor, R. K., C. Manoil, and J. J. Mekalanos. 1989. Broad-host-range vectors for delivery of TnphoA: use in genetic analysis of secreted virulence determinants of Vibrio cholerae. J. Bacteriol. 171:1870-1878.

14. Sambrook, J., E. F. Fritsch, T. Maniatis. 1989. Molecular Cloning: A laboratory Manual. Cold Spring Harbor Press, Cold Spring Harbor, New York. A.1.

15. Thompson, M. R., H. Brandwein, M. LaBine-Racke, and R. A. Giannella 1984. Simple and reliable enzyme-linked immunosorbent assay with monoclonal antibodies for detection of Escherichia coli heat-stable enterotoxins. J. Clin. Microbiol. 20:59-64.

16. Alderete, J. F., and D. C. Robertson. 1977. Nutrition and enterotoxin synthesis by enterotoxigenic strains of Escherichia coli: defined medium for production of heat-stable enterotoxin. Infect. Immun. 15:781-788.

17. Guandalini, S., J. F. Kechur, P. L. Smith, and M. Field 1980. Somatostatin effects on ion transport in rabbit intestine. Am. J. Physiol. 240:G26-G32.

18. Field, M., and I. McCall. 1971. Ion transport in rabbit ileal mucosa: I. Na and $\mathrm{Cl}$ fluxes and short-circuit current. Am. J. Physiol. 220:1388-1396.

19. Brandwein, H., A. Deutsch, M. R. Thompson, and R. A. Giannella. 1985. Production of neutralizing monoclonal antibodies to Escherichia coli heat-stable enterotoxin. Infect. Immun. 47:242-246.

20. Moseley, S. L., P. Echeverria, J. Seriwatana, C. Tirapat, W. Chaicumpa, T. Sakuldaipeara, and S. Falkow. 1982. Identification of enterotoxigenic Escherichia coli by colony hybridization using three enterotoxin gene probes. J. Infect. Dis. 145:863-869.

21. Thompson, M. R., R. L. Jordan, M. A. Luttrell, H. Brandwein, J. B. Kaper, M. M. Levine, and R. A. Giannella. 1986. Blinded, two-laboratory comparative analysis of Escherichia coli heat-stable enterotoxin production by using monoclonal antibody enzyme-linked immunosorbent assay, radioimmunoassay, suckling mouse assay, and gene probes. J. Clin. Microbiol. 24:753-758.
22. Feinberg, A. P., and B. Vogelstein. 1983. A technique for radiolabeling DNA restriction endonuclease fragments to high specific activity. Anal. Biochem. 132:6-13.

23. Maas, R. 1983. An improved colony hybridization method with signifcantly increased sensitivity for detection of single genes. Plasmid. 10:296-298.

24. Moseley, S. L., I. Huq, A. R. M. A. Alim, M. So, M. Samadpour-Motalebi, and S. Falkow. 1980. Detection of enterotoxigenic Escherichia coli by DNA colony hybridization. J. Infect. Dis. 142:892-898.

25. Lockwood, D. E., and D. C. Robertson. 1984. Development of a competitive enzyme-linked immunosorbent assay (ELISA) for Escherichia coli heatstable enterotoxin (STa). J. Immunol. Methods. 75:295-307.

26. Okamoto, K., A. Miyama, T. Takeda, Y. Takeda, and T. Miwatani. 1983 Cross-neutralization of heat-stable enterotoxin activity of enterotoxigenic Escherichia coli and Yersinia enterocolitica. FEMS (Fed. Eur. Microbiol. Soc.) Microbiol. Lett. 16:85-87.

27. Arita, M., T. Takeda, T. Honda, and T. Miwatani. 1986. Purification and characterization of Vibrio cholerae Non-01 heat-stable enterotoxin. Infect. Immun. 52:45-49.

28. Guarino, A., S. Guandalini, M. Alessio, F. Gentile, L. Tarallo, G. Capano, M. Migliavacca, and A. Rubino. 1989. Characteristics and mechanism of action of a heat-stable enterotoxin produced by Klebsiella pneumoniae from infants with secretory diarrhea. Pediatr. Res. 25:514-518.

29. Guarino, A., R. Giannella, and M. R. Thompson. 1989. Citrobacter freundii produces an 18-amino-acid heat-stable enterotoxin identical to the 18-aminoacid Escherichia coli heat-stable enterotoxin (ST Ia). Infect. Immun. 57:649-652.

30. Rao, M. C., and M. Field. 1984. Enterotoxins and ion transport. Biochem. Soc. Trans. 12:177-180.

31. Weikel, C. S., H. N. Nellans, and R. L. Guerrant. 1986. In vivo and in vitro effects of a novel enterotoxin, STb, produced by Escherichia coli. J. Infect. Dis. 153:893-901.

32. Wanke, C. A., R. L. Guerrant. 1989. Enterotoxigenic Escherichia coli. In Enteric Infections. M. J. G. Farthing, and G. T. Keusch, editors. Chapman and Hall, Cambridge. 253-263.

33. Baudry B., S. J. Savarino, P. Vial, J. B. Kaper, and M. M. Levine. 1990. sensitive and specific DNA probe to identify enteroaggregative Escherichia coli, a recently discovered diarrheal pathogen. J. Infect. Dis. 161:1249-1251. 